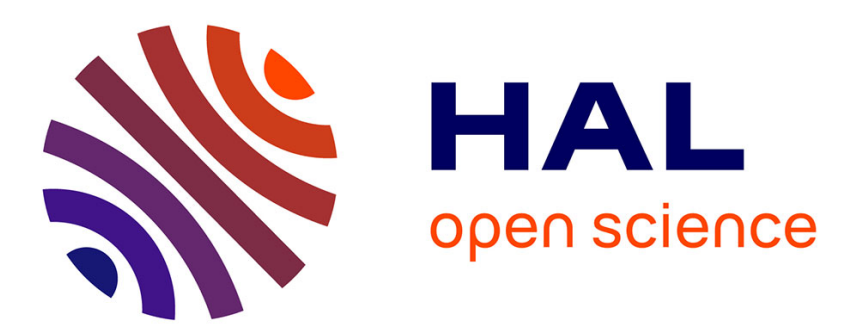

\title{
NMR imaging of fluid pathways during drainage of softwood in a pressure membrane chamber
}

Giana Almeida, Sébastien Leclerc, Patrick Perre

\section{To cite this version:}

Giana Almeida, Sébastien Leclerc, Patrick Perre. NMR imaging of fluid pathways during drainage of softwood in a pressure membrane chamber. International Journal of Multiphase Flow, 2008, 34, pp.312 - 321. 10.1016/j.ijmultiphaseflow.2007.10.009 . hal-01482134

\section{HAL Id: hal-01482134 \\ https://hal.univ-lorraine.fr/hal-01482134}

Submitted on 3 Mar 2017

HAL is a multi-disciplinary open access archive for the deposit and dissemination of scientific research documents, whether they are published or not. The documents may come from teaching and research institutions in France or abroad, or from public or private research centers.
L'archive ouverte pluridisciplinaire HAL, est destinée au dépôt et à la diffusion de documents scientifiques de niveau recherche, publiés ou non, émanant des établissements d'enseignement et de recherche français ou étrangers, des laboratoires publics ou privés. 


\title{
NMR IMAGING OF FLUID PATHWAYS DURING DRAINAGE OF SOFTWOOD IN A PRESSURE MEMBRANE CHAMBER
}

\author{
G. ALMEIDA ${ }^{\mathrm{a}}$, S. LECLERC ${ }^{\mathrm{b}}$, P. PERRE ${ }^{\mathrm{c}}$ \\ a Laboratório de Química, Celulose e Energia, Escola Superior de Agricultura «Luiz \\ de Queiroz », Universidade de São Paulo (ESALQ/USP), Av.: Pádua Dias, 11 CP \\ 9 Piracicaba, Brasil - almeida@ nancy-engref.inra.fr \\ b Laboratoire d'Énergétique et de Mécanique Théorique et Appliquée (LEMTA), \\ UMR 7563 CNRS - Nancy Université, INPL, BP 160, Vandoeuvre-les-Nancy, \\ France - Sebastien.Leclerc@rmn.uhp-nancy.fr \\ ${ }^{c}$ Laboratoire d'Etudes et de Recherche sur le Matériau Bois (LERMAB), UMR \\ INRA/ENGREF/UHP 1093, ENGREF, 14 rue Girardet, Nancy, France - \\ perre@nancy-engref.inra.fr \\ ${ }^{1}$ Corresponding author : Tel : +33 3833968 90; Fax: +33 383396847
}

\begin{abstract}
An experiment was implemented to study fluid flow in a pressure media. This procedure successfully combines nuclear magnetic resonance imaging with a porous membrane chamber in order to visualize the non-wetting and wetting fluid flows with controlled boundary conditions. A specific pressure minute membrane chamber, made of non magnetic materials and able to withstand $4 \mathrm{MPa}$, was conceived and built for this purpose. These two techniques were applied to the drainage of Douglas fir sapwood. In the study of the longitudinal flow, narrow drainage fingers are formed in the latewood zones. They follow the longitudinal direction of wood and spread throughout the sample length. These fingers then enlarge in the cross-section plane and coalesce until drainage reach the whole latewood part. At the end of the essays, when drainage of liquid water in latewood is completed, just a few sites of percolation appear in earlywood zones. This
\end{abstract}


difference is a result of the wood anatomical structure, where pits, the apertures that allow the sap to flow between wood cells, are more easily aspirated in earlywood than in latewood.

Keywords: NMR imaging, Pressure membrane, Porous media, Douglas fir, Multiphase flow, Percolation network

\section{INTRODUCTION}

To understand the mechanisms affecting the fluid flow in a porous media is very important for several applications such as drying and impregnation processes. Wood is a representative example of porous media, whose cellular structure is composed by a pore network joined by narrower connecting throats (pits). Softwood species have much greater uniformity than hardwoods. The principal structure of softwoods is the longitudinal tracheids, with approximately $92 \%$ of the volumetric composition. These elements have a length of about $3500 \mu \mathrm{m}$ and a cross-sectional diameter of about $30 \mu \mathrm{m}$. Due to the wood physiology, tracheids formed during summer (latewood) have cell walls much thicker than those formed during spring (earlywood). Indeed, the double cell wall increases from about $4 \mu \mathrm{m}$ in earlywood to more than $10 \mu \mathrm{m}$ in latewood. This difference highly affects its physical and mechanical properties. Tracheids are connected by bordered pits, which consist of two complementary gaps or recesses in the cell walls. These pits are covered with a membrane much thinner than the rest of the cell wall called torus. The torus is surrounded by the annular margo consisting of microfibrillar strands with openings between them permitting the passage of liquids between the cells (Siau, 
1995). If a gas/liquid interface passes through the pit, the capillary forces cause the membrane to move into the aspirated position, closing off the water flow. In the living tree, this feature exists to limit the damage due to cavitation in the sap column. In the wood material pit aspiration inhibits the liquid flow and is often problematic (drying, preservation...).

Nuclear magnetic resonance imaging (MRI) is a non-destructive and a non-invasive technique that has been widely used to determine moisture distribution and fluid flow through a porous medium. For example, MRI has been used to study the flow through a porous medium in many fields including ground water hydrology, petroleum engineering, and soil science (Williams et al., 1991; Waggoner and Fukushima, 1996; Kimmich et al,. 2001; Chen et al,. 2002; Deurer et al., 2002). The majority of these works study the displacement of two immiscible fluids using a reference liquid and/or glass beads to simulate the porous medium. For example, Chen et al. (2002) used a model consisted by artificial consolidates sandstone saturated with oil. Oil in the model was flooded by an aqueous paramagnetic ion solution $\left(500 \mathrm{mg} \cdot \mathrm{L}^{-1}\right.$ of $\mathrm{MnCl}_{2}$ ) at a constant flux of 0.25 $\mathrm{mL} \cdot \mathrm{min}^{-1}$ and the distribution of the two phases at different stages of the water flooding was determined. A column filled with glass beads was used to study water flow in porous media by Deurer et al. (2002). In this study, water was pumped through the glass beads with a Pharmacia double syringe pump at rates of 125 and $250 \mathrm{~mL} \cdot \mathrm{h}^{-1}$.

Wood can be successfully imaged by MRI because of its relatively regular structure, in particular thanks to its almost self-similar structure obtained by a translation in the longitudinal direction. Nuclear magnetic resonance signal in green wood may be separated into three major components: solid wood (fast decreasing signal), cell-wall 
water (medium signal) and lumen water (slow signal). Several works used this technique to make the separation of the sapwood and heartwood, description of growth rings and visualisation of internal defects or anomalies of wood (Kuroda et al., 2006; Eberhardt et al., 2006). MRI was also used for non-invasive qualitative and quantitative studies of water distribution in wood and wood-drying kinetics (Quick et al., 1990; Meder et al., 2003; van Houts et al., 2004; Merela et al., 2005).

During experiment of fluid flow in porous media, the accurate control of the boundary conditions is a difficult task, especially at high humidity levels. The present work uses the pressure membrane principle to study the water flow in wood at high relative humidities. Although this method is mostly used on soil science (ASTM, 2000), it has been successfully used by many researchers in the studies of wood-water relationships (Robertson, 1965; Stone and Scallan, 1967; Griffin, 1977; Fortin, 1979; Almeida and Hernández, 2006).

The present work combines MRI with an accurate method to control the drainage inside a porous medium (Douglas fir). This combination permits the displacement of the wetting phase by an overpressure of the non-wetting phase to be observed. The 3-D images of the moisture content fields versus time provide new insights in the fluid migration mechanisms taking place in softwood: cluster formation, coalescence of cluster, absence of liquid migration in earlywood... To our knowledge, this is the first time that these phenomena can be observed by non-destructive methods and with a rigorous control of drainage conditions. 


\section{MATERIAL AND METHODS}

Douglas fir (Pseudotsuga menziesii) sapwood samples were cut from a green log. Longitudinal and radial specimens were turned using a lathe (Figure 1A). A diamond wire saw (Well model 3241, ESCIL) was used to cut the cylindrical samples. The final dimensions of the longitudinal specimens were $17 \mathrm{~mm}$ in diameter and $20 \mathrm{~mm}$ in length (parallel to the longitudinal tracheids) and for the radial ones were $17 \mathrm{~mm}$ in diameter and $15 \mathrm{~mm}$ in length (parallel to the radial elements). In order to maintain the green state, the samples were soaked in distillated water until the test. The test material had an average basic wood density (oven-dry mass to green volume) of $467 \mathrm{~kg} \cdot \mathrm{m}^{-3}$ (coefficient of variation $(\mathrm{CV})$ of $5 \%)$.

\subsection{Experiments}

\section{Pressure membrane principle}

The pressure membrane principle is used to control the water state in a porous medium at high humidity levels $(>95 \% \mathrm{RH})$ or to apply a pressure difference between the wetting phase and the non-wetting phase. This principle lies in the concept of water potential $(\psi)$, which is derived from classical thermodynamics and defined as the difference between the specific Gibbs free energy of water in the state under study and in a standard reference state (Siau, 1995). The reference state generally used is a hypothetical pool of pure free water at atmospheric pressure, at a given elevation and at the same temperature as that of the water in the porous material (Fortin, 1979). The water potential is normally expressed in terms of energy per unit mass in $\mathrm{J}_{\mathrm{kg}} \mathrm{kg}^{-1}$. The water potential of moist air may be deduced from Kelvin's law (equ. 1). 


$$
\psi=\frac{R T \ln h}{M_{w}}
$$

where: $\mathrm{R}$ is the gas constant $\left(8.31 \mathrm{~J} \cdot \mathrm{mol}^{-1} \cdot \mathrm{K}^{-1}\right) ; T$ is the absolute temperature $(\mathrm{K}) ; h$ is the relative vapor pressure and $M_{w}$ is the molar mass of water $\left(18 \times 10^{-3} \mathrm{~kg} \cdot \mathrm{mol}^{-1}\right)$.

Equation (1) relates the relative humidity and the pressure difference between liquid and gas. From this equation, the equivalent radius of curvature of the air-water meniscus can be calculated by Laplace's law. This equivalent radius $r$ is defined by the radius of a cylindrical tube which produces the same pressure difference:

$$
r=\frac{-2 \gamma \cos \theta}{\rho_{w} \psi}
$$

where: $\gamma$ is the surface tension of water/air interface $\left(0.072{\mathrm{~N} . \mathrm{m}^{-1}}^{-1} 25^{\circ} \mathrm{C}\right), \theta$ is the contact angle between the liquid and the surface of the capillary ( $0^{\circ}$ for a perfectly wetting fluid) and $\rho_{w}$ is the normal density of water $\left(\mathrm{kg} \cdot \mathrm{m}^{-3}\right)$.

A pressure chamber, integrally made of non-magnetic and electrical isolating materials, was specially designed in order to make possible the use of the pressure membrane principle inside the NMR spectrometer (Figure 1B). This chamber was designed for a maximal capacity of $4 \mathrm{MPa}$. The nitrogen pressure was controlled by manometers, which are connected to the pressure chamber by a $1.6 \mathrm{~mm}$ diameter Teflon tube.

The longitudinal or radial samples were placed into the pressure chamber on two saturated membranes of different pore diameters (membrane $1=20 \mu \mathrm{m}$; membrane $2=$ $0.025 \mu \mathrm{m})$ (Figure 1B). The solely role of membrane 1, with coarse pores, is to protect 
the active membrane. The latter effectively withstands the pressure chamber. The system works until the pressure remains below the percolation pressure of the membrane. The one we used, with a diameter of $0.025 \mu \mathrm{m}$, is able to operate up to about $10 \mathrm{MPa}$ at $25^{\circ} \mathrm{C}$. A saturated clay layer of about $1 \mathrm{~mm}$ thick was placed on membrane 1 in order to ensure hydraulic contact with the specimen. Pressure was then gradually applied until the required level was reached. A maximal pressure of $500 \mathrm{kPa}$ was applied in this work. At this pressure, capillaries with a radius larger than $0.288 \mu \mathrm{m}$ are empties (equ. 2). Specimens were weighted before and after the pressure membrane/MRI essays and were oven-dried at $102^{\circ} \mathrm{C}$ until equilibrium to determine the moisture content.

\section{MRI analysis}

Magnetic Resonance Imaging experiments were carried on a Bruker Biospec 24/40 spectrometer equipped with a homemade gradient coil and a $3.5 \mathrm{~cm}$ diameter resonator. The pressure chamber was designed to fit precisely in this probe and thus avoiding vibration artefacts during the experiment.

Relaxation times in saturated parts of wood were measured using inversion recovery method for longitudinal relaxation time $\left(\mathrm{T}_{1}\right)$ and Carr Purcell Meiboon Gill method for transverse relaxation time $\left(\mathrm{T}_{2}\right)$. The values measured were $240 \mathrm{~ms}$ for $\mathrm{T}_{1}$ and $37 \mathrm{~ms}$ for $\mathrm{T}_{2}$

Images were acquired using a classical multi-slice spin-echo experiments with the following parameters: repetition time (TR) : 1s, echo time (TE) : $18.3 \mathrm{~ms}$, field of view (FOV) : 4cm, matrix : 256*192 points, spatial resolution $156 * 208 \mu \mathrm{m}$. The repetition time TR was chosen sufficiently long to avoid longitudinal relaxation contrast. TE was chosen long enough to suppress signal coming from bound water and short enough to minimize 
$\mathrm{T}_{2}$ contrast. Nevertheless, there is still a small decrease in the signal of the lumen water due to transverse relaxation

Magnetic resonance imaging acquisition consisted of 3 slices with an effective thickness of $2 \mathrm{~mm}$ and a $5 \mathrm{~mm}$ inter-slice distance (Figures $2 \mathrm{~A}$ and $\mathrm{B}$ ). The total scan time for imaging acquisition was 3 minutes. A glass tube ( $4.5 \mathrm{~mm}$ of internal diameter) containing $5 \mathrm{mM}$ copper sulfate dissolved in water was used as reference image. Copper sulfate was used to shorten longitudinal relaxation times to a value of $100 \mathrm{~ms}$ and transverse relaxation time to $45 \mathrm{~ms}$. The grey level obtained in water $\left(1.8 \times 10^{6}\right.$ arbitrary unit) allowed us to convert the grey levels of wood images into volumetric water content. For example, we found $1.3 \times 10^{6}$ (arbitrary unit) as density in saturated parts of earlywood. This corresponds to an apparent water density of $720 \mathrm{~kg} \cdot \mathrm{m}^{-3}$. Due to the very short relaxation time of bound water, this value includes only liquid water. Assuming that the bound water content at saturation and the cell wall density are equal to $30 \%$ (dry basis) and $1500 \mathrm{~kg} \cdot \mathrm{m}^{-3}$, respectively (Siau, 1995), we obtain a basic wood density (oven-dry mass to green volume) in earlywood equal to $320 \mathrm{~kg} \cdot \mathrm{m}^{-3}$. This value is in very good agreement with literature data (Bosshard, 1984; Gartner et al., 2002).

\section{Anatomical measurements}

Duplicate samples were taken next, in longitudinal direction, to those used for the pressure membrane/IRM analysis. They were examined using an environmental scanning electron microscope (ESEM, FEI Quanta 200) located at Engref/Nancy. Uncoated samples were observed at a voltage below $10 \mathrm{kV}$ and a chamber pressure of 1 Torr using a large field gaseous detector (secondary electrons). Cross-sectional images at different 
magnifications were taken in order to measure cell diameters and cell wall thickness of earlywood, latewood, and ray parenchyma.

\section{RESULTS}

Images obtained by MRI and ESEM are presented in Figure 3A and 3B-3D, respectively. The signal obtained in the MRI technique consists of mostly, if not entirely, liquid water (also called to free water in wood science) present in the lumen of the wood specimen. Bound water and solid wood were not visible due to their rapidly decaying signal in contrast to the slowly decaying signal of the liquid water. In the MRI figures presented in this work, lighter colors mean higher quantity of liquid water. The average moisture content was initially equal to $156 \%(\mathrm{CV}$ of $1 \%)$ and $110 \%(\mathrm{CV}$ of $4 \%$ ) at the end of the experiment (average of 3 tests realized on longitudinal direction).

Due to their differences in anatomical structure, earlywood and latewood areas are easily distinguished on the images (Figure 3A). Earlywood presents thin cell walls and large lumen diameters, whereas latewood has thick cell walls and small lumen diameter (Figure 3B and 3C). The decay signal for liquid water in the cell lumens has been found to be roughly proportional to the cell lumen diameter on different wood species (Menon et al., 1987; Flibotte et al., 1990; Almeida et al., 2007). Figures 3A, 3B and 3D also exhibit false rings within annual growth rings. They correspond to pause in secondary growth rate due to climatic conditions, such as drought.

The evolution of water drainage in the longitudinal direction is showed in Figure 4. These raw data represent the signal intensity in the 3 slices at different drainage times. 10 minutes after the pressure was applied, first drainage spots (dark areas) can be observed on one of the latewood rings. It should be notice that these drainage spots can be 
observed on the three slices (along the specimen), showing the flow connectivity in the latewood tracheids. These drainage zones then spread in the transverse plane until coalescence occurs $(30 \mathrm{mn})$. At this time, the water proportion in earlywood remains unchanged. This is surprising because this part of the annual ring is reputed to have a much higher permeability than the latewood part. At the end of the essay, 270 minutes, all latewood parts are fully drained. At this time, some drainage spots just appear in one of the earlywood zones. However, the observation of the 3 slices proves that these drainage spots are still not connected along the specimen's length.

A better representation of these experimental data is proposed in Figure 5. To prepare this figure, a small application program was developed to convert the grey levels of each image in apparent specific gravity values using the calibration procedure explained in the previous section. The same application allows the three slices to be saved in a 3-D data files using the Tecplot software. The views depicted in Figure 5 consist of 3 slices (flood contours of 5 values regularly spread from 0.12 to 0.68 apparent specific gravity) plus one 3-D isovalue (0.12), which allows the shape of the drained zones to be pictured. For the sake of visibility, the cut-off color possibility proposed by Tecplot was activated : zones below 0.12 are not colored in the slices.

Before pressure is applied, the three slices are similar, in which the great water content difference between earlywood (0.6 to 0.8 ) and latewood (0.3 to 0.5$)$ is evident. After 10 minutes of drainage, the water content field already decreased significantly in earlywood zones of slice 1, where the pressure is applied. Thin fingerings are obvious throughout the sample length in one latewood zone. The 0.12 isovalue surface proves that 
the drained spots observed on the images are perfectly aligned along the longitudinal direction of wood.

At 20 minutes, no clear evolution has to be noticed, except that the narrow fingers had time to spread and now tend to coalesce in the transverse plane. This tendency is confirmed after 1 hour of drainage : at this instant, the latewood zone of this annual ring lost almost all its liquid (or free) water content. However, isolated water clusters appear : they will remain up to the end of the essay. Although the time required for the second latewood zone to be drained is more longer (100 minutes), the mechanism seems to be identical, with the appearance of narrow fingers spreading throughout the sample length.

At the end of the test (270 minutes), the two latewood zones present a bimodal pattern, with isolated water clusters existing inside a fully drained zone. In the second latewood zone, these water clusters remain connected in the tangential direction, along the false ring. At this time, one earlywood zone just starts to be drained. Again, the drainage mechanism seems to be identical, with the existence of narrow spots. Even though they are not yet entirely connected in the longitudinal direction, the contour patterns of the different slices prove that the longitudinal connection indeed exists.

As above discussed, the first clusters of drainage are observed in the same latewood ring. These first drainage clusters and a magnification of the latewood ring can be observed on Figures $6 \mathrm{~A}$ and $6 \mathrm{~B}$, respectively. Some irregularities in the diameter of the latewood tracheids (false latewood ring) are also observed on Figure 6B. Analyzing these figures, one can observe that the percolation network starts on the latewood tracheids of larger diameters, whose are more permeable than the smaller ones. 
The longitudinal drainage also gives us information about the drainage of radial parenchyma (Figure 4). This drainage is only observed on slice 1, where cut rays are next to the nitrogen inflow. Slice 1 (Figures 4 and 5) also shows that earlywood next to the nitrogen inflow has less liquid water than earlywood of slices 2 and 3.

Results of water drainage in the radial direction are presented in Figures 7A (before pressure application), 7B (10 minutes after a pressure application of $500 \mathrm{kPa})$ and $7 \mathrm{~B}(80$ minutes after pressure application). Even if this essay favored radial flow, comparison between these figures shows superficial flow along the tracheids (longitudinal direction) and homogenization of humidity inside the sample. After 80 minutes of essay, the radial drainage is not observed. Several works have reported the ray parenchyma as being the least permeable tissue in the wood structure (Hart et al., 1974; Gonzalez and Siau, 1978; Wheeler, 1982; Siau, 1995; Almeida and Hernandez, 2006), Figure 7 corroborates results of these works.

\section{DISCUSSION}

Results presented in Figures 4 and 5 definitely prove that the easy ways for drainage are in latewood. At first glance, this is surprising because it is well-known that earlywood is the most permeable part of softwoods in the case of single phase flow. Another feature of fluid flow in wood has therefore to be considered to explain our observations. To induce the ascent of sap in tree, the menisci present in the leaf stomata pull up water. Because most trees are more than $10 \mathrm{~m}$ high, one can deduce that the absolute liquid pressure in the sap column is negative. No gaseous phase can exist in such conditions, which renders this sap column very fragile. Indeed, the vascular system is such that the tree must be able to support a gas invasion due to injury or cavitation. In softwoods, this 
is the role of bordered pits. These bordered pits are specialized valves : in the case of single phase flow (sap flow) they are permeable, but they close off (this is called pit aspiration) by capillary forces when a liquid/gas meniscus passes through it. In latewood, the small and thick membranes (torus) and strands of the bordered pits might not allow them to act as a valve. Indeed, the low resistance of latewood zones to embolism in the living tree and the higher drainage of these zones in the wood are a consequence of the structural features of the bordered pit membrane (Perré and Turner, 2001; Domec and Gartner, 2002; Usta, 2005).

Drainage consists in the immiscible displacement of a wetting fluid by a non-wetting fluid. In this configuration, capillary forces act against the flow. For slow displacements (capillary regime), capillary forces prevail and the front shape is controlled by the heterogeneity of the pore sizes along the interface. When the displacing fluid is less viscous than the displaced fluid, viscous forces destabilize the interface as the flow rate increases (viscous regime). The capillary number $\mathrm{Ca}$ can be used to distinguish these two regimes. This number is usually expressed as follows (Dullien, 1992) :

$$
C a=\frac{\text { Viscous forces }}{\text { Capillary forces }}=\frac{v \mu_{w}}{\sigma \cos \theta}
$$

where: $v$ and $\mu_{w}$ are the velocity and viscosity, respectively, of the wetting fluid; $\sigma$ is the water-gas interfacial tension and $\theta$ is the contact angle $\left(0^{\circ}\right.$ here because water perfectly wets the wood substance).

Finally, the gravity can also stabilize or destabilize the interface, but its effect can be discarded in our experiments because the main flow is horizontal and the sample depth involves a very small pressure difference in comparison with the applied pressure. 
In our experiment of wood drainage by nitrogen, it is not obvious whether fingering results from a viscous regime or a capillary regime. Our viscous ratio ( $\kappa=\mu_{w} / \mu_{n w} \approx 50$ at $20^{\circ} \mathrm{C}$ ) and the rapid breakthrough of the non-wetting fluid into the wetting fluid suggest that a viscous regime could take place (Lenormand et al., 1988). Calculating $\mathrm{Ca}$ needs the velocity to be evaluated. Two methods could be used :

- to evaluate the fluid velocity of the active pores (about 10 minutes for the first fingers to cross the $20 \mathrm{~mm}$ sample length) $: v_{1}=3 \cdot 3 \cdot 10^{-5} \mathrm{~m} \cdot \mathrm{s}^{-1}$,

- to consider the initial velocity (single fluid phase and intrinsic permeability) using Darcy's law. Assuming the longitudinal permeability in Douglas fir to be $10^{-13} \mathrm{~m}^{2}$ and its porosity 0.66 , we obtain $v_{2}=2 \cdot 5 \cdot 10^{-3} \mathrm{~m} \cdot \mathrm{s}^{-1}$.

In fact, $v_{2}$ is certainly overestimated, at first because the calculation neglects the resistance due to the membranes and the clay layer, and because a multiphase flow configuration takes place as soon as the experiment starts. Relative permeability factors should be added, that reduces considerably the medium permeability to each fluid phase.

Retaining value $v_{1}$, the capillary number, $\mathrm{Ca}$, is equal to $4.5 \cdot 10^{-8}$. Referring, with care, to literature data (Lenormand et al., 1988), this value seems too low to produce viscous fingering. It seems therefore that capillary fingering is responsible for the thin fingers observed here. The fact that the drainage of second latewood zone, then of the first earlywood zone, present similar patterns is an additional argument in the favor of capillary fingering. These zones are indeed drained in a much longer time, which reduces the capillary number by more than one order of magnitude.

The long and narrow shape of fingers is therefore certainly due to the strong anisotropy of wood : crossing one pit allows the flow to progress of about $2 \mathrm{~mm}$ in 
longitudinal direction and only of about $50 \mu \mathrm{m}$ in the cross sectional plane. Once a pathway exist along the sample length, it allows gradual transverse drainage, from one tracheid to its neighbor : one open pit is enough for this lateral drainage, instead of at least two (one at each cell end) for longitudinal migration. Finally, entrapped water clusters can be analyzed as groups of tracheids without unaspirated pits.

During most of the experimental time, earlywood zones seemed to be completely impervious. This observation was analyzed as the high proportion of aspirated pits in this part of wood. Therefore, the late drainage of one earlywood zone denotes that, in spite of aspiration, the pits are not perfectly impervious. Some leakage does exist, namely in minute opening that continue to exist in aspirated pits, between the torus and the cell wall. The applied pressure (500 $\mathrm{kPa})$ is able to force the meniscus to path in pores whose radius is above $0.288 \mu \mathrm{m}$ (equ. 2).

\section{CONCLUSION}

A procedure was developed to visualize fluid flow through a porous media. This procedure combines two techniques, namely, NMR imaging and pressure membrane. Thus, the present work shows the displacement of the wetting phase by application of the non-wetting phase in Douglas fir samples. Earlywood and latewood are easily distinguished in the images obtained. The procedure presented in this work successfully shows the longitudinal flow inside a porous media. Clusters of drainage are first formed in the latewood zones, these clusters are longitudinally connected. Drainage zones in latewood increase until the coalescence. In the end of the essays, drainage of liquid water in latewood is completed and few sites of percolation are observed in earlywood zones. 
This result is a consequence of the wood anatomical structure, where earlywood pits are easier aspirated then latewood ones.

\section{ACKNOWLEDGMENTS}

This work was supported by the State of São Paulo Research Foundation (FAPESP) and Federation of Research Jacques Villermaux. The authors are grateful to Professor Yves Fortin (Laval University, Quebec, Canada) for valuable suggestions about the pressure membrane method. The authors would also like to thanks the Nancy I University NMR service for the use of the Bruker Biospec.

\section{REFERENCES}

Almeida, G., Hernández, R.E., 2006. Changes in physical properties of yellow birch below and above the fiber saturation point, Wood Fiber Sci, 38(1): 74-83.

Almeida, G., Gagné, S., Hernández, R.E., 2007. A NMR study of water distribution in hardwoods at several equilibrium moisture contents. Wood Sci Technol. DOI 10.1007/s00226-006-0116-3.

ASTM, 2000. D3152-72(2000) Standard Test Method for Capillary-Moisture Relationships for Fine-Textured Soils by Pressure-Membrane Apparatus. American Society for Testing and Materials, West Conshohocken, PA.

Bosshard, H. H., 1984. Holzkunde, Band: 2 : Zur Biologie, Physik und Chemie des Holzes, Birkhäuser, Basel.

Chen, Q., Kinzelbach, W., Oswald, S., 2002. Nuclear Magnetic Resonance Imaging for Studies of Flow and Transport in Porous Media. J. Environ. Qual. 31:477-486.

Deurer, M., Vogeler, I., Khrapitchev, A., Scotter, D., 2002. Imaging of Water Flow in Porous Media by Magnetic Resonance Imaging Microscopy. J. Environ. Qual. 31:487-493.

Domec, J-C., and Gartner, B.L., 2002. How do water transport and water storage differ in coniferous earlywood and latewood? Journal of Experimental Botany, Vol. 53 (379):2369-2379.

Dullien, F.A.L., 1992. Porous Media: Fluid Transport and Pore Structure, Second Edition, Academic Press, San Diego. 574 p.

Eberhardt, T.L., So, C.L., Herlihy, A.H., So, P.W., 2006. Use of gadolinium chloride as a contrast agent for imaging spruce knots by magnetic resonance. Wood and Fiber Science, 38(3): 527-534. 
Flibotte, S., Menon, R.S., MacKay, A.L., Hailey, J.R.T., 1990. Proton magnetic resonance of western red cedar. Wood Fiber Sci 22(4):362-376

Fortin, Y., 1979. Moisture content-water potential relationship and water flow properties of wood at high moisture contents. Thèse de Ph.D. Université de British Columbia, Vancouver. 187 p.

Gartner, B.L., North, E.M., Johnson, G.R., Singleton, R., 2002. Effects of live crown on vertical patterns of wood density and growth in Douglas-fir. Can. J. For. Res. 32: 439-447.

Griffin, D.M., 1977. Water potential and wood-decay fungi. Annual Review of Phytopathology, 15:319-329.

Gonzalez, G.C., Siau J.F., 1978. Longitudinal liquid permeability of American beech and eucalyptus. Wood Sci 11(2):105-110.

Hart, C.A., Przestrzelski, P.J., Wheeler, F.J., 1974. Entrapped lumen water in hickory during desorption. Wood Sci 6(4):356-362.

Kimmich, R., Klemm, A., Weber, M., 2001. Flow, diffusion, and thermal convection in percolation clusters: NMR experiments and numerical FEM/FVM simulations. Magn Reson Imaging , 19: 353-361.

Kuroda, K., Kanbara, Y., Inoue, T., Ogawa, A., 2006. Magnetic resonance micro-imaging of xylem sap distribution and necrotic lesions in tree stems. IAWA Journal, 27 (1), 2006: 3-17.

Lenormand, R., Touboul, E., Zarcone, C., 1988. Numerical models and experiments on immiscible displacement in porous media. J. Fluid Mechanics ;189:165-187.

Meder, R., Codd, S.L., Franich, R.A., Callaghan, P.T., Pope, J.M., 2003. Observation of anisotropic water movement in Pinus radiate D. Don sapwood above fiber saturation using magnetic resonance micro-imaging. Holz als Roh- und Werkstoff, 61: 251-256. DOI 10.1007/s00107-003-0400-y

Menon, R.S., Mackay, A.L., Hailey, J.R.T., Bloom, M., Burgess, A.E., Swanson, J.S., 1987. An NMR determination of the physiological water distribution in wood during drying. J Appl Polym Sci 33(4):1141-1155.

Merela, M., Sepe, A., Oven, P., Serša, I., 2005. Three-dimensional in vivo magnetic resonance microscopy of beech (Fagus sylvatica L.) wood. Magma 18(4):171-174.

Perré, P., Turner, I., 2001. Determination of the material property variations across the growth ring of softwood for use in a heterogeneous drying model. Part I : capillary pressure, tracheid model and absolute permeability, Holzforschung, 55: 318-323.

Quick, J.J., Hailey, J.R.T., MacKay, A.L., 1990. Radial moisture profiles of cedar sapwood during drying: a proton magnetic resonance study. Wood and Fiber Science, 22(4):404-412.

Robertson, A.A., 1965. Investigation of the cellulose-water relationship by the pressure plate method. Tappi, 48(1):68-573. 
Siau, J.F., 1995. Wood: Influence of moisture on physical properties. Virginia Polytechnic Institute and State University, VA. 227 p.

Stone, J.E., Scallan, A.M., 1967. The effect of component removal upon the porous structure of the cell wall of wood. II. Swelling in water and the fiber saturation point. Tappi, 50(10):496-501.

Usta, I., 2005. A review of the configuration of bordered pits to stimulate the fluid flow, Maderas. Ciencia y tecnología, 7(2): 121-132.

van Houts, J.H., Wang, S., Shi, H., Pan, H., Kabalka, G.W., 2004. Moisture movement and thickness swelling in oriented strandboard, part 1. Analysis using nuclear magnetic resonance microimaging. Wood Sci Technol, 38: 617-628.

Waggoner, R.A., Fukushima, E., 1996. Velocity distribution of slow fluid flows in Bentheimer sandstone: an NMRI and propagator study. Magnetic Resonance Imaging, 14 (9): 1085-1091.

Wheeler, EA., 1982. Ultrastructural characteristics of red maple (Acer rubrum L.) wood. Wood Fiber Sci 14(1):43-53.

Williams, J.L.A., Taylor, D.G., Maddinelli, G., Enwere, P., Archer, J.S., 1991. Visualization of fluid displacement in rock cores by NMR imaging. Magn. Reson. Imaging, 9:767-773. 


\section{LEGENDS OF FIGURES}

Figure 1. (A) Scheme of samples placement in the wood stem. (B) Scheme of the pressure chamber used in the pressure membrane/IRM tests.

Figure 2. Configuration of the specimens inside the pressure chamber showing the flow direction and position (slice) of IRM acquisition. (A) Longitudinal flow. (B) Radial flow.

Figure 3. Transversal section images of Douglas fir specimen. (A) NMR image showing dark latewood and light coloured earlywood. (B-D) ESEM micrographs: (B-C) earlywood (EW) and latewood (LW) zones, (D) irregularity of cell diameters in the latewood zone (false growth ring).

Figure 4. Evolution of water drainage (longitudinal flow) in three positions (slices) of the specimen. White arrows indicate percolation spot in the latewood zone. The black arrow depicts the beginning of drainage clusters in earlywood at the end of the essay. The white square (top left) is the magnified zone exhibited in figure 5 .

Figure 5. Three-dimensional MRI of apparent water specific gravity at 6 different drainage times. This magnified zone is specified by a square in figure 4 (top left).

Figure 6. Transversal section of Douglas fir. (A) IRM showing the first percolation network (arrow). (B) ESEM micrograph (the box highlights the region where the first percolation network was observed). 
Figure 7. Tangential-longitudinal section of Douglas fir (radial flow). (A) IRM before pressure application (slice 2). (B) IRM after 10 minutes of pressure application (slice 2). (C) IRM after 80 minutes of pressure application (slice 2). 
(A)

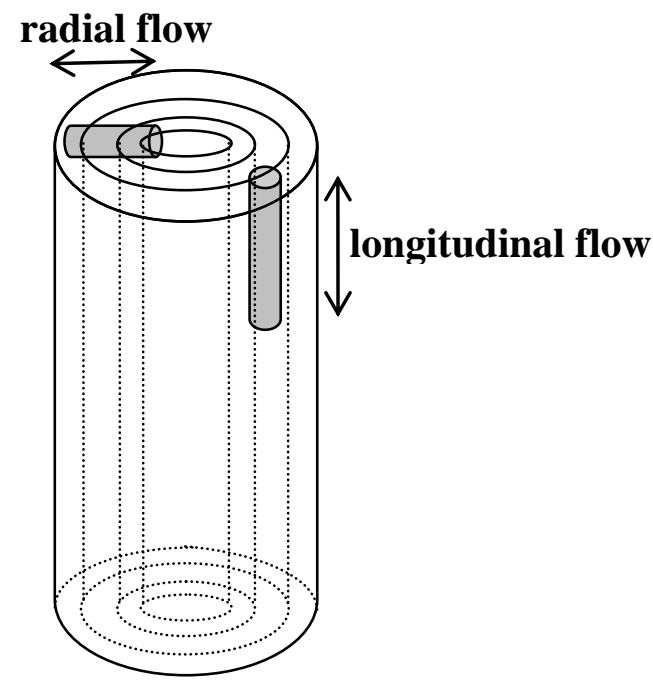

(B)

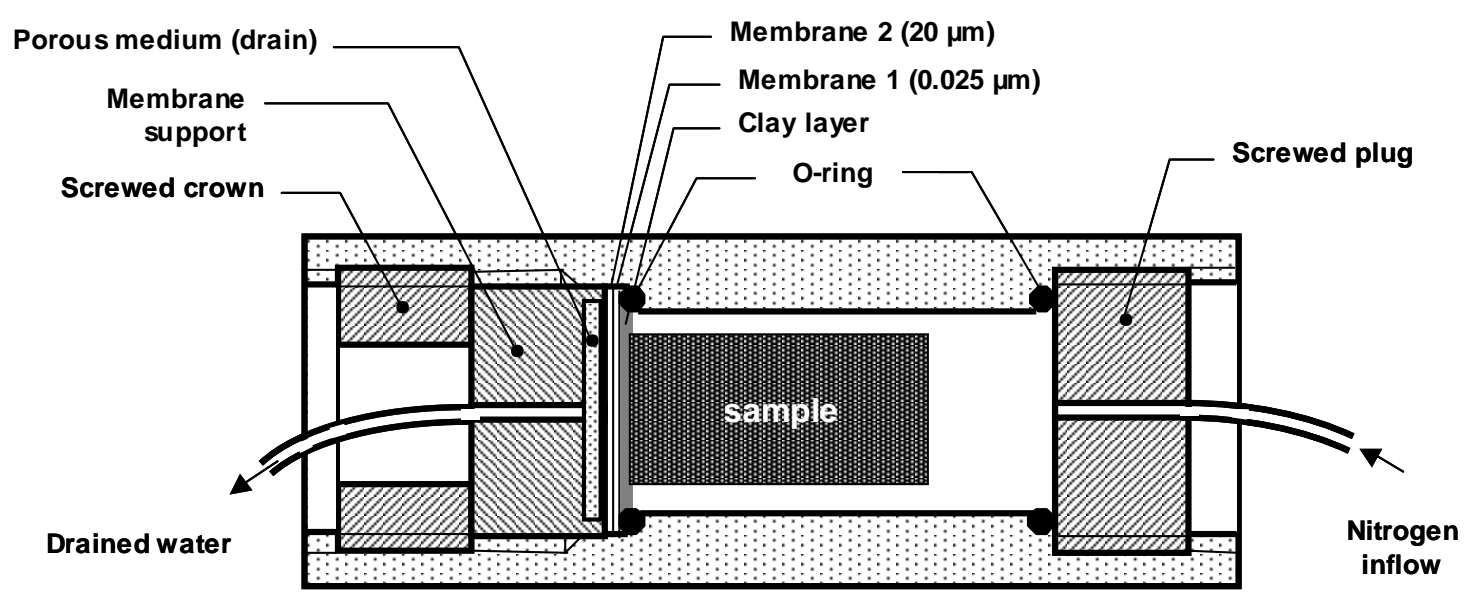


Figure 8. (A) Scheme of samples placement in the wood stem. (B) Scheme of the pressure chamber used in the pressure membrane/IRM tests. 


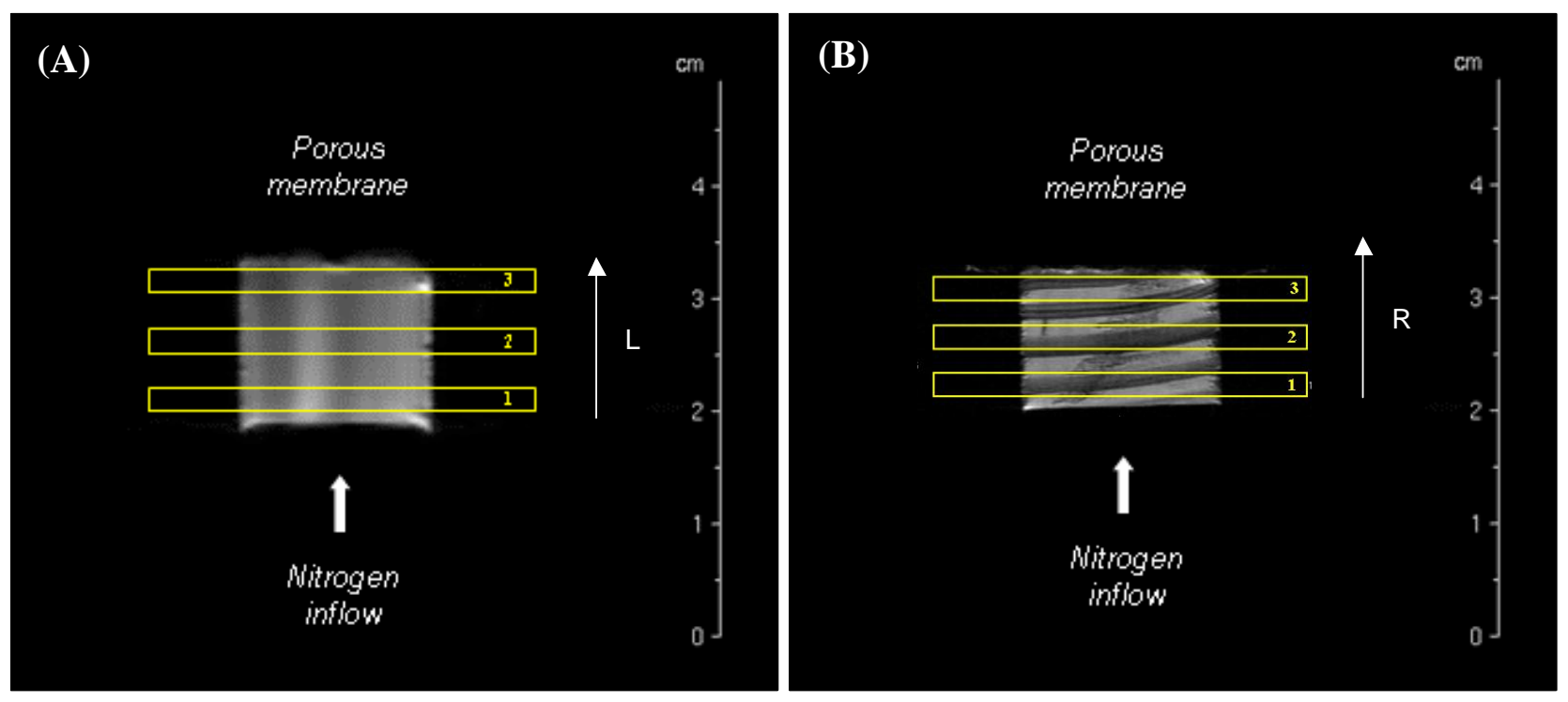

Figure 9. Configuration of the specimens inside the pressure chamber showing the flow direction and position (slice) of IRM acquisition. (A) Longitudinal flow. (B) Radial flow. 


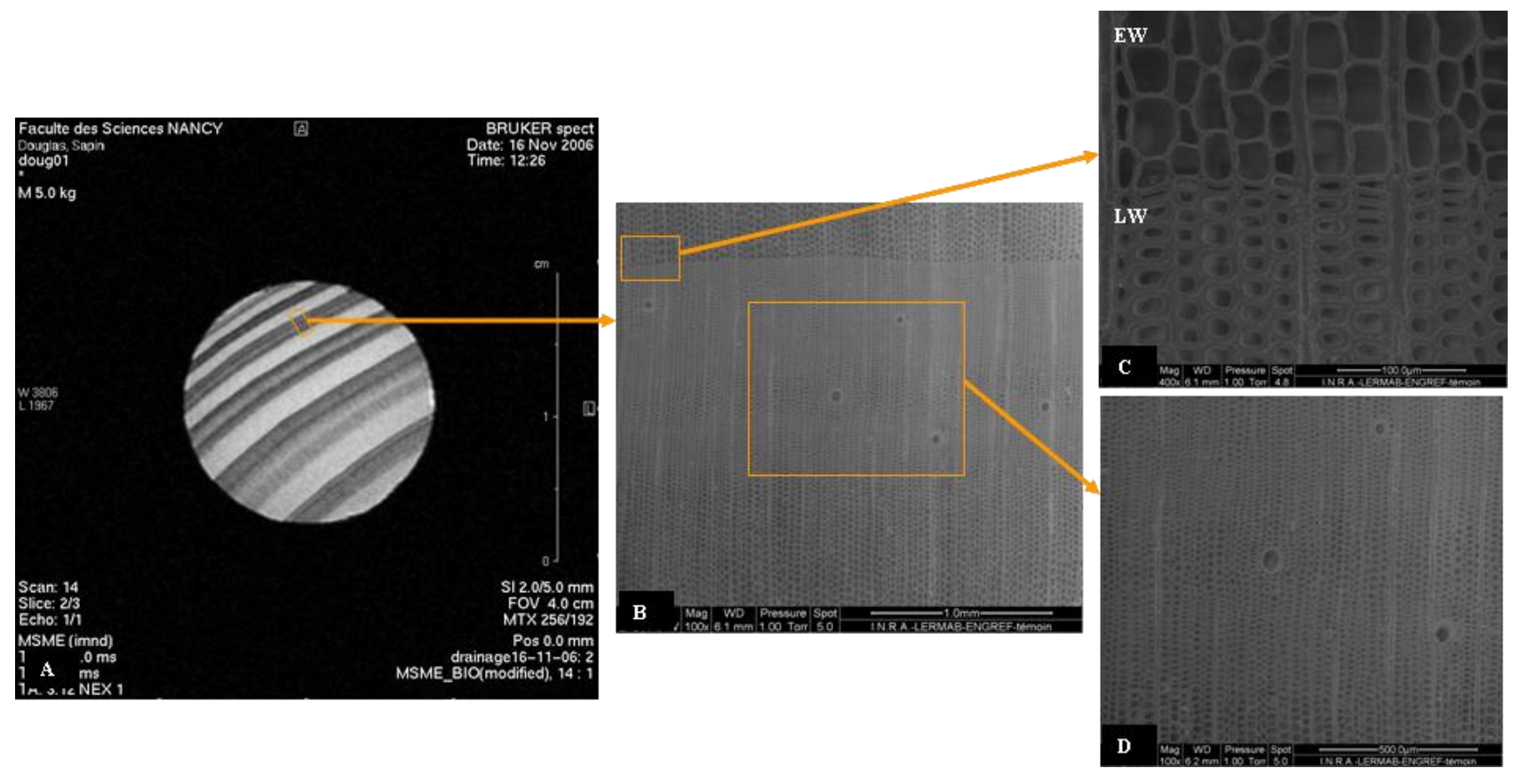

Figure 10. Transversal section images of Douglas fir specimen. (A) NMR image showing dark latewood and light coloured earlywood. (B-D) ESEM micrographs: (B-C) earlywood (EW) and latewood (LW) zones, (D) irregularity of cell diameters in the latewood zone (false growth ring). 
Slice 1
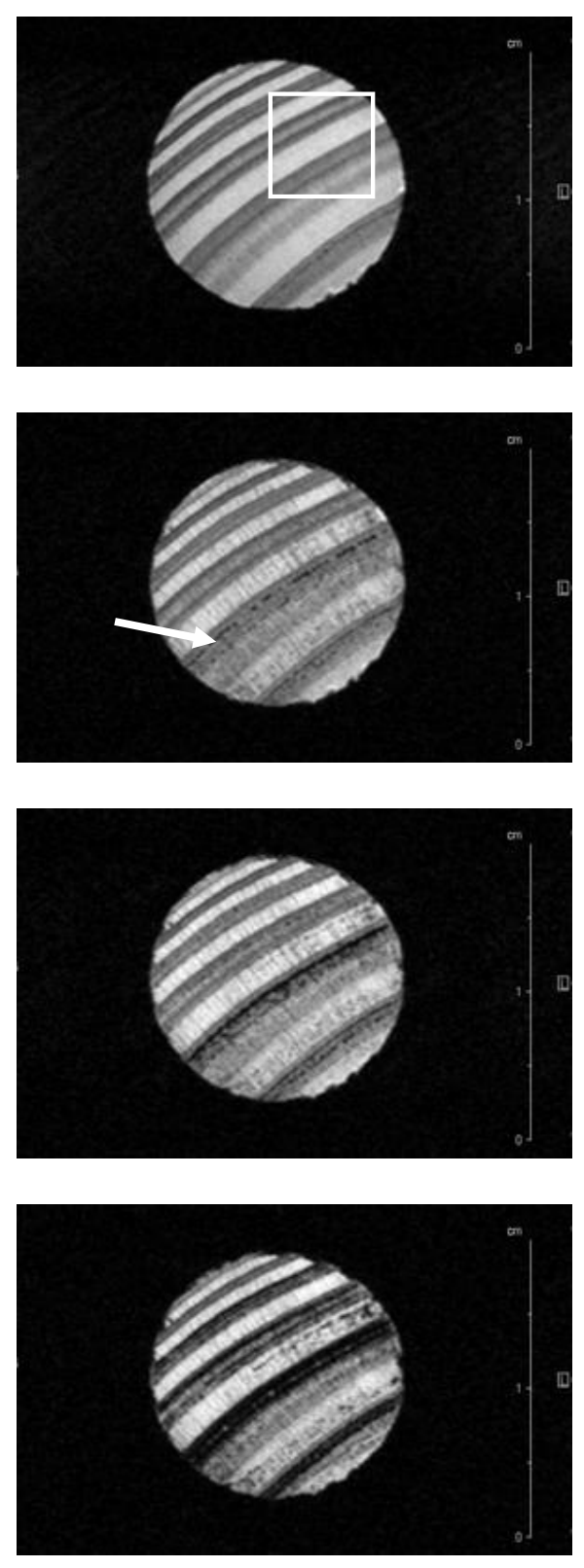

Slice 2

Before pressure application

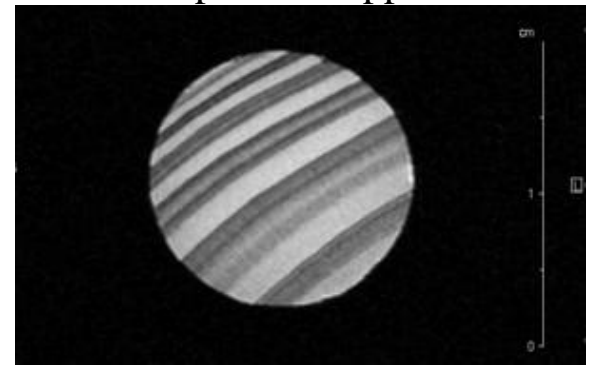

10 minutes of drainage

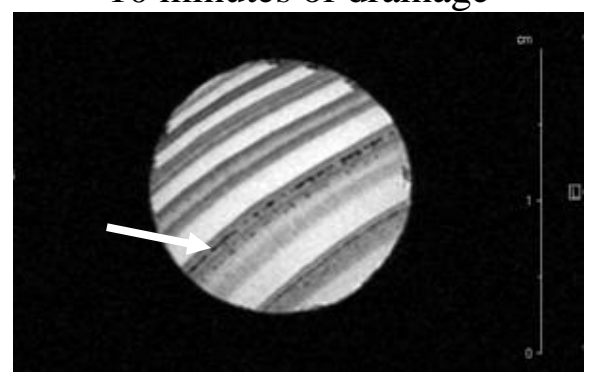

30 minutes of drainage

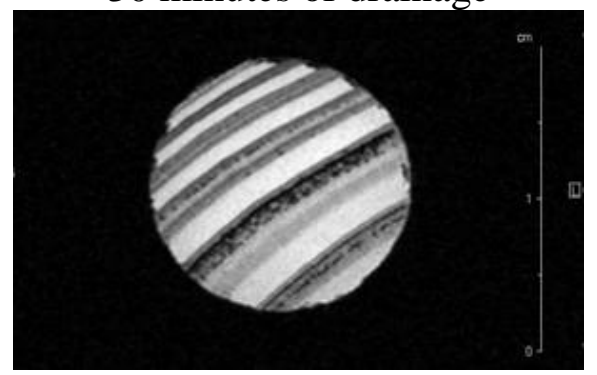

270 minutes of drainage

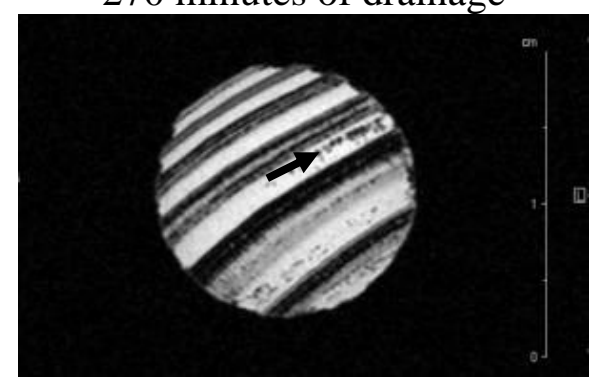

Slice 3
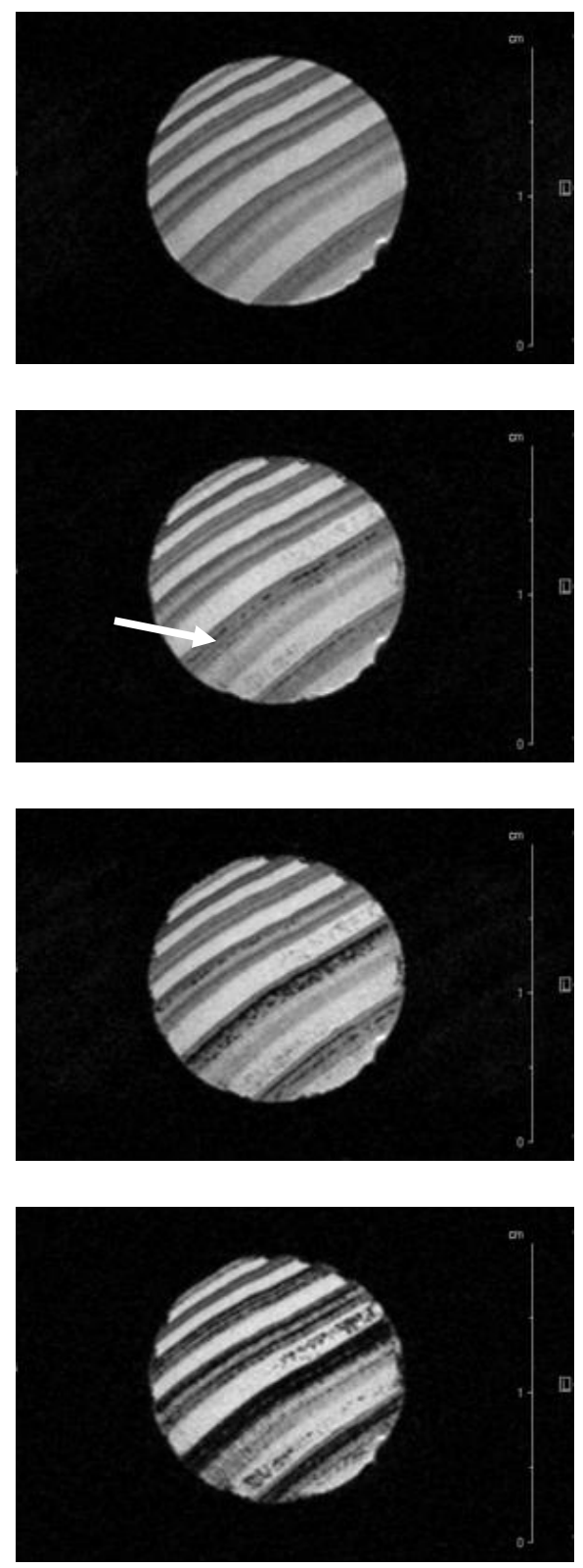

Figure 11. Evolution of water drainage (longitudinal flow) in three positions (slices) of the specimen. White arrows indicate percolation spot in the latewood zone. The black arrow depicts the beginning of drainage clusters in earlywood at the end of the essay. The white square (top left) is the magnified zone exhibited in figure 5. 

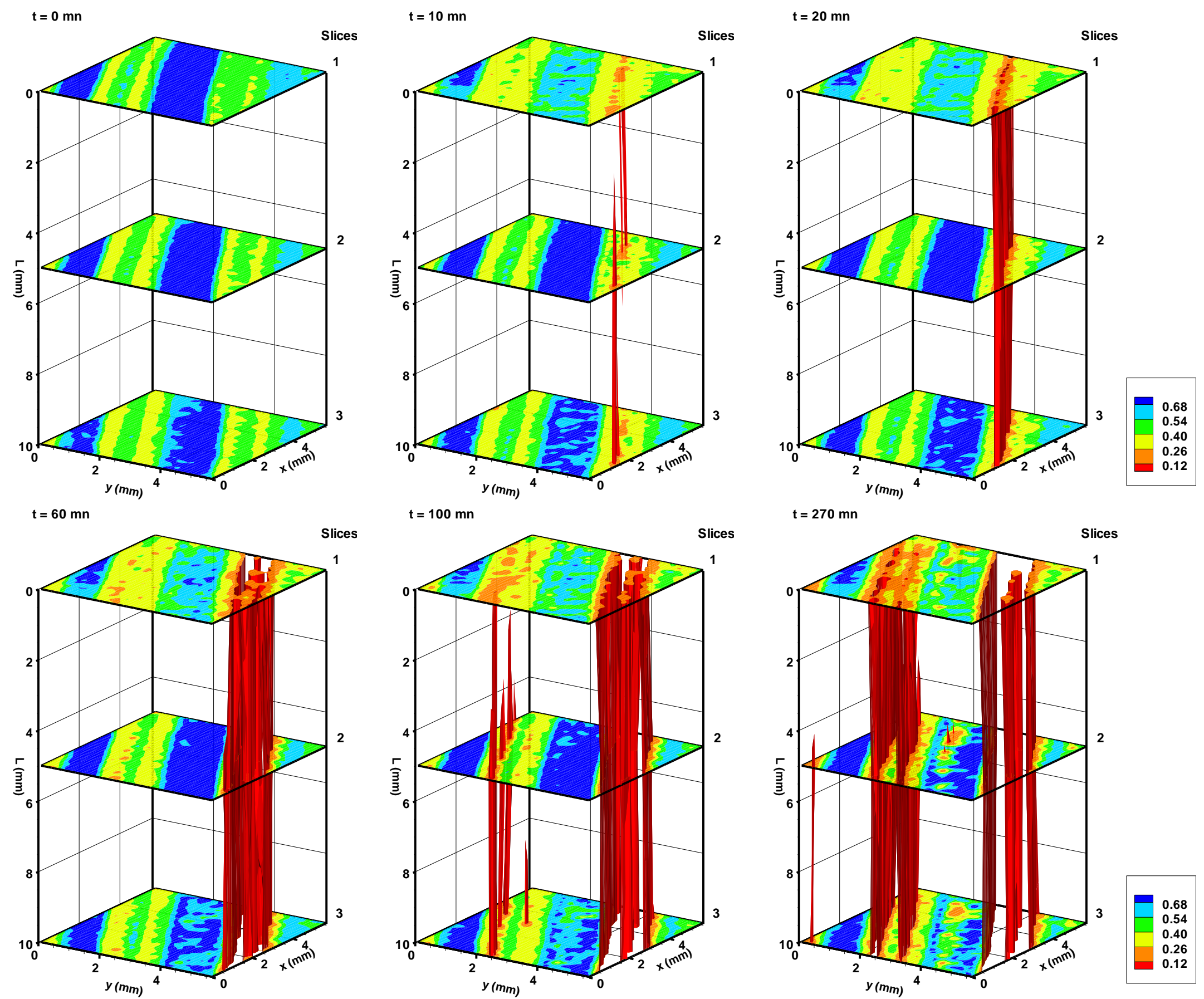

Figure 12. Three-dimensional MRI of apparent water specific gravity at 6 different drainage times. This magnified zone is specified by a square in figure 4 (top left). 


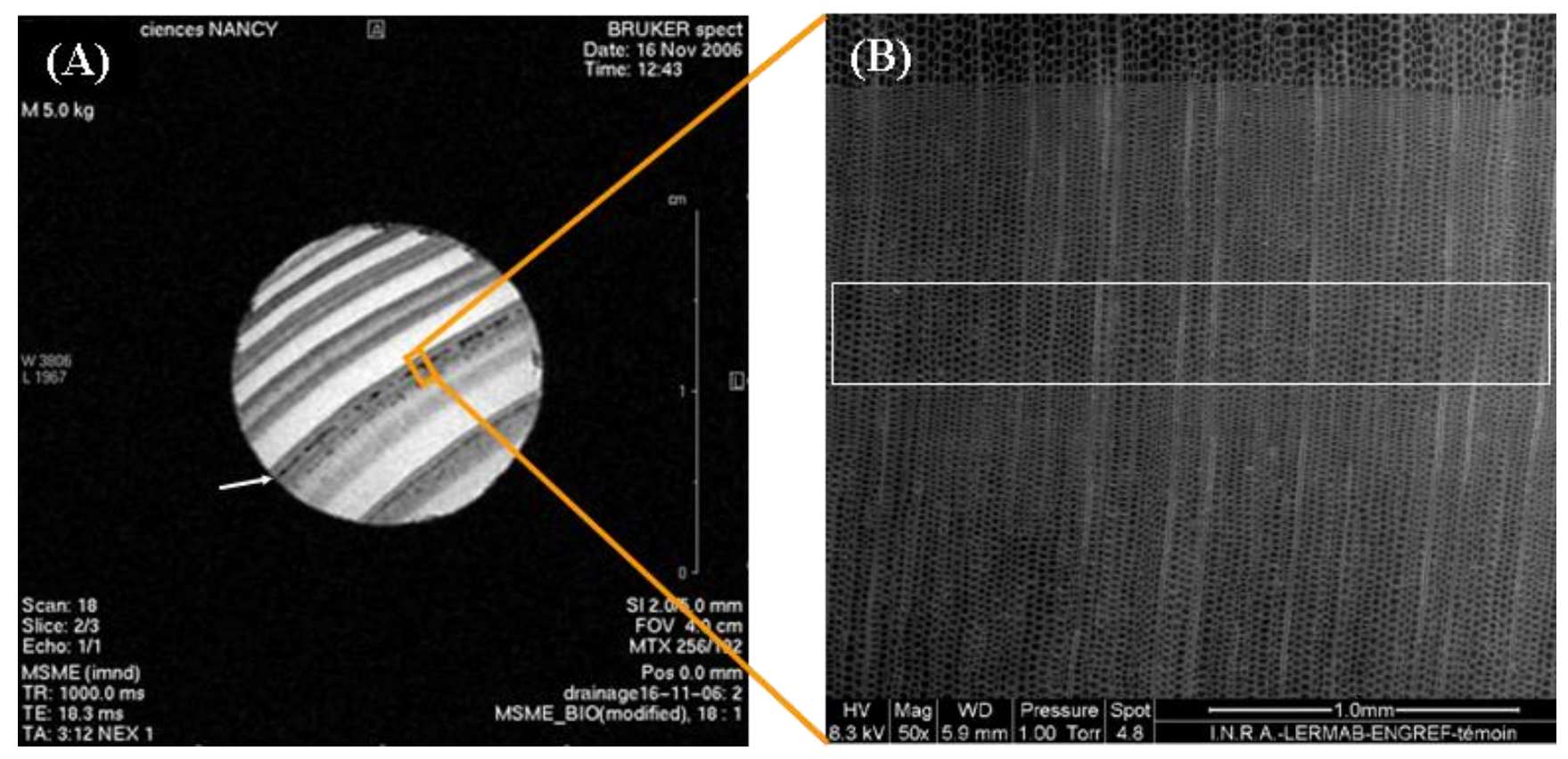

Figure 13. Transversal section of Douglas fir. (A) IRM showing the first percolation network (arrow). (B) ESEM micrograph (the box highlights the region where the first percolation network was observed). 

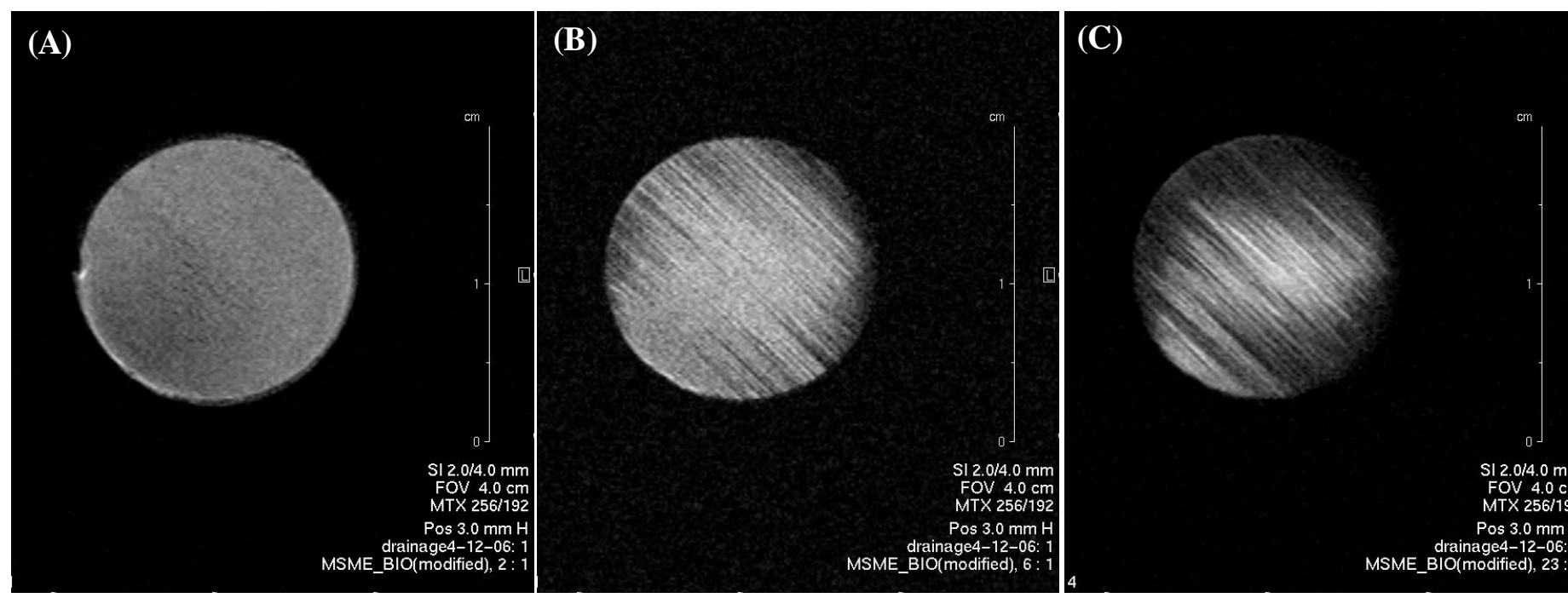

Figure 14. Tangential-longitudinal section of Douglas fir (radial flow). (A) IRM before pressure application (slice 2). (B) IRM after 10 minutes of pressure application (slice 2). (C) IRM after 80 minutes of pressure application (slice 2 ). 